\title{
EDITORIAL
}

https://doi.org/10.22395/ojum.v19n38al

\section{¿Cuáles son las exigencias de los pueblos latinoamericanos? Llegar a ser algo}

Cuando se escribe este editorial, América Latina está convulsionada. Movimientos sociales se han puesto en marcha en Perú, Ecuador, Chile y Colombia para expresar su inconformidad con gobiernos de derecha e izquierda. Mucho se ha escrito en los últimos años acerca de la crisis de la democracia (Levittsky y Ziblatt, 2018; Mendieta, 2019). ¿Pero están las democracias latinoamericanas en crisis o ni siquiera hemos podido consolidarlas pues siguen siendo las democracias de unos pocos? Tenemos gobernantes elegidos democráticamente, pero también necesidades básicas insatisfechas, pobreza, desigualdad y falta de oportunidades.

Según el índice Gini', que mide la concentración de riquezas a nivel global (Banco Mundial, 2017), nuestros países son increíblemente desiguales: Brasil $(0,53)$, Colombia $(0,49)$, Venezuela $(0,46)$, Chile $(0,46)$, Ecuador $(0,44)$, Bolivia $(0,44)$, Perú $(0,43)$ y Argentina $(0,41)$. Para las Naciones Unidas, la concentración de riqueza superior a 0,4 es preocupante porque denota la concentración de riquezas en unos pocos, lo que podría llevar al descontento de la mayoría. La pobreza en Latinoamérica va en aumento. Hemos pasado de 30,1 \% de población pobre y 10,7 \% en extrema pobreza en el año 2015 a 30,8 \% y 11,5\% respetivamente en el 2019, según datos de la Cepal (2019). Lo que significa que mientras el número de pobres aumenta en la región, al mismo tiempo se concentra la riqueza en unos pocos y, por tanto, crece la desigualdad.

Pueden existir muchas razones para protestar: reclamar el regreso a la institucionalidad en Perú, que no suba la gasolina en Ecuador, pedir una nueva Constitución en Chile o estar en contra de las medidas económicas en Colombia. Pero en todos los casos hay un elemento común: un pueblo que quiere hacerse oír. Vale la pena recordar a Sieyès (1789) y el comienzo de su obra ¿Qué es el Tercer Estado?:

\footnotetext{
El índice Gini utiliza el coeficiente que lleva el mismo nombre multiplicado por cien. Fue creado por Corrado Gini con el propósito de medir cualquier forma de distribución desigual. El índice es un número entre cero y cien, donde cero es la igualdad plena y cien es la mayor desigualdad.
} 
El plan de este escrito es ciertamente sencillo. Debemos responder a tres preguntas:

1. ¿Qué es el Tercer Estado? Todo.

2. ¿Qué ha sido hasta el presente en el orden político? Nada.

3. ¿Cuáles son sus exigencias? Llegar a ser algo. (p. 3)

En todas las constituciones de la región el pueblo es soberano, pero solo en el papel, pues en la práctica se ha buscado históricamente favorecer a las élites. Luego de cientos de años de exclusión, primero colonial y ahora social, los pueblos latinoamericanos quieren ser escuchados, quieren llegar a ser algo.

Opinión Jurídica se une al clamor de una región y reitera la importancia de la ciencia como instrumento de cambio social. En este sentido, pone a consideración de la comunidad científica y académica el número 38, el cual cuenta con investigaciones sobre derecho penal, criminología y criminalística tales como: "Thoughts and observations of punishment in contemporary criminal law" (Estados Unidos), "Segurança e justiça: o acordo de não persecução penal e sua compatibilidade com o sistema acusatório" (Brasil), "Informática criminalística: una especialidad en desarrollo" (Cuba) y "Colonialidade e feminicídio: superação do "Ego Conquiro" como desafio ao Direito" (Brasil). Para este número, algunos de nuestros autores abordaron problemas propios de los derechos humanos en contextos nacionales e internaciones, es el caso de "Derechos humanos para el desarrollo de una sociedad realmente globalizada" (Brasil), "Consecuencias del cambio en el sexo legal en el sistema de salud colombiano" (Colombia), "O licenciamento ambiental como política pública e o poder das empresas" (Brasil), "Barreras para el acceso a prestaciones por accidente de trabajo en el Sistema General de Riesgos Laborales en Colombia para un trabajador informal" (Colombia) y "Aplicación y límites de la inmunidad diplomática, a la luz de las normas del ius cogens" (Colombia). En este número también se tratan temas relacionados con el acuerdo de paz celebrado hace tres años entre el Estado colombiano y las FARC-EP. Este es el caso de "Retos del posconflicto frente a la respuesta humanitaria: entre la persistencia de las consecuencias humanitarias y las limitaciones al mandato de los actores humanitarios" (Colombia) y "El enfoque diferencial étnico y el deber de la consulta previa en el acuerdo de paz" (Colombia y Brasil). Nos complace aportar a discusiones propias de la filosofía del derecho con el artículo "Lenguaje y derecho. Una lectura teológicopolítica a partir de Walter Benjamin" (Colombia) y del derecho procesal con "La Ley de Procedimiento Administrativo y el monopolio postal" (Chile). Son trece artículos hechos por autores de Brasil, Chile, Colombia, Cuba y Estados Unidos; escritos en inglés, español y portugués. Queremos ser parte de la construcción de una América Latina unida por la ciencia, con sociedades más justas e incluyentes, donde el conocimiento permita que los pueblos sean libres.

David Mendieta

Editor 


\section{REFERENCIAS}

Banco Mundial. (2017). Índice de Gini. Consultado el 11 de febrero de 2011. https://datos.bancomundial. org/indicador/SI.POV.GINI?view $=$ map\&year $=2017$

Cepal. (2019). Panorama Social en America Latina, 2019. Consultado el 11 de febrero de 2020. https://repositorio.cepal.org/bitstream/handle/11362/44969/4/S1900908_es.pdf

Levittsky, S. y Ziblatt, D. (2018). Cómo mueren las democracias. Ariel

Mendieta, D. (2019). A Crise da Democracia e do Sistema de Freios e Contrapesos nos Estados Unidos. En L. G. Arcaro, R. Dias (Coords.), Crise das democracias liberais: perspectivas para os direitos fundamentais e separacao de poderes/ organizadores (pp. 220-232). Lumen Juris.

Sieyès, E. (1789). ¿Qué es el Tercer Estado? Consultado el 11 de febrero de 2020. http://www. elblogdederecho.com/wp-content/uploads/2013/12/sieyes-que-es-el-tercer-estado.pdf 